\title{
Study on Humanistic Spirit of Sports and Sports Modernization
}

\author{
Hongmei $\mathrm{Sun}^{1}$, Zichen $\mathrm{Hu}^{2}$ \\ ${ }^{1}$ Zhenjiang College, Zhenjiang, Jiangsu, 212003 \\ ${ }^{2}$ Southwest University of Political Science \& Law, Chongqing, 401120
}

\section{Keywords: Sports Spirit, Sports Modernization, Humanistic Spirit}

\begin{abstract}
The phenomenon of alienation in modern sports is a universal characteristic derived from the formation and development of modern sports. These characteristics reflect the deficiency and deficiency of humanistic spirit in modern sports. And to effectively eliminate these alienation, we must cultivate the humanistic spirit in sports, not only to emphasize the re-understanding of sports itself, more important is to reflect the eternal value of sports humanistic spirit. The realization of this eternal value and aesthetic education is inseparable. In order to eliminate the phenomenon of alienation in modern sports and to analyze the eternal value of sports humanistic spirit from aesthetic education function. The paper expounds the necessity of raising the humanistic spirit of sports, the sports humanistic characteristics of aesthetic education, the relationship between aesthetic education and the cultivation of humanistic spirit of sports.
\end{abstract}

\section{Introduction}

In the past 10 years, scholars, scholars, scholars and other specialists have devoted their contents to the relationship between humanistic spirit, humanistic spirit and humanities, the relationship between humanistic spirit and scientific spirit, the similarities and differences between Chinese and Western humanities and the connotation of modern humanistic spirit Problem, published a lot of insight. It is particularly important to explore and utilize traditional human resources. As a deep-rooted tradition, the humanistic thought has been deeply into the Chinese culture and the Chinese people's bone marrow, about people's way of thinking and behavior, for the construction of modern humanistic spirit, has a very important impact. China's highest level of humanistic has care the value of time and space beyond. Humanistic spirit gives the Chinese culture tenacious vitality, so that Chinese culture, the Chinese people through the vicissitudes of life, suffering, but always climax after another, inherited endless. Therefore, the ancient tradition contains a rich humanistic spirit, is our construction of modern humanistic spirit of the important cultural resources, we need to explore and use. With the development of modern society, the division of the global knowledge system, specialization intensified, leading to the division of science and humanities, intellectuals for professional reasons more and more lack of humanistic care. Therefore, China's famous educator Mr. Yang Shuzi in Huazhong University of Science and Technology pioneered to strengthen humanistic education, attracted people's attention and thinking. It inherited the tradition of Chinese culture, the construction of modern sports humanistic spirit, with the world Olympic Games humanistic dialogue of the practical significance. The modern humanistic spirit pursues the high degree of harmony and unity of truth, goodness and beauty with thorough humanitarianism as the supreme principle. Sports, especially the Olympic no doubt the pursuit of the highest realm of life: truth, goodness, beauty and harmony. 


\section{The Development of Sports Humanistic Spirit is the Realization of Sports Modernization}

Sports modernization is one of the main goals to be achieved in the development of sports activities. It is necessary to integrate into a large number of advanced science and technology in the process of sports modernization. It needs to integrate a large number of advanced humanistic ideas, and it is a comprehensive and strong, And the complex system, and the humanistic spirit of sports is an essential part of its indispensable part, while its modernization of sports also play an important role in this, such as through the culture of humanistic spirit of training and improvement can be effective Norms, and strengthen the majority of sportsmen's love of sports activities, as well as the social development of the sense of mission, sense of responsibility, honor, etc., while the humanistic spirit of sports athletes have professional ethics, honesty and trustworthiness, civilized and courteous requirements, all reflect The development of modern development under the requirements of human moral standards, it can be said that the cultural humanistic spirit of sports modernization is an important soft power. In the context of a high degree of modernization of economic and social development, the construction of sports hardware facilities is often much simpler than the soft power, and the construction of software facilities is much simpler. Therefore, the construction of sports modernization should not only have modern hardware facilities with high technology, Requiring athletes with a high level of sports humanistic spirit. After the modernization of the humanistic spirit of the athletes, in order to truly achieve the goal of sports modernization. In the third industrial revolution, the world has entered the period of humanism development, talent will become a business, a country's main driving force for development, the traditional mechanical production will also be replaced by humanism, and the importance of humanism Is recognized by the world, such as China's Haier Group Chairman said that in the development of Haier Group to firmly grasp the two things: the first thing is to continue to improve corporate culture, we can see, human Doctrine, humanistic spirit has penetrated into all areas of economic and social development, become an important spiritual power of economic and social development. In the course of sports modernization, we also need to draw lessons from the successful development of enterprises, effectively integrate sports modernization and sports humanistic spirit construction, so as to realize interaction, and constantly strengthen the humanistic spirit as the core sports culture Construction and modernization of sports construction, imagine, in the future development process, the important role of sports humanistic spirit will be more and more prominent, by constantly strengthening the construction of sports humanistic spirit, can effectively improve the moral level of sports, sports professional quality and A national sports team cohesion, in order to achieve high level, high professional level of the event. With the deepening of the implementation of China's reform and opening up national policy, Western culture is also broadly into the country, the conflict between the East and West culture is inevitable, so, to combine the humanistic spirit of sports, sports modernization needs, To accommodate the Western charm of the culture, into a modern sports with Chinese characteristics, and ultimately the formation of China's unique sports humanistic spirit, modern sports culture.

\section{Sports Humanistic Spirit is the Spiritual Motive Force of Sports Modernization Development}

Sports modernization is a comprehensive system, the humanistic spirit of sports is an indispensable part, which regulates the athletes on sports, social sense of responsibility, sense of justice, sense of mission, honor, etc .; on the athlete's personal dignity, values, Ideal mood, civilized consciousness, sports moral standards, honesty and credit, civilized and courteous requirements, belonging to the sports modernization of the software part. In a sense, sports modernization software is difficult to 
hardware, when the athlete's personal sports spirit to achieve the spirit of the human spirit, to show the results of the modernization of sports in order to show the style of sports culture in order to show the community into the ranks of modernization. Since the introduction of humanism in the process of modern industrialization in the world, the schools of classical management, traditional management and decision management have been created, which has promoted the leap in management thought in the field of sports management activities. Contemporary enterprises take the lead in recognizing the leading role of humanistic spirit in the survival and development of enterprises, and Japan and the United States have become the birthplace of corporate culture. Called Chinese corporate culture Haier Group Chairman Zhang Ruimin said he was in charge of Haier only caught two things, one of which is the corporate culture. These shows that the humanistic spirit has penetrated into the social and economic activities, is the spiritual power of social development.

The modernization of sports makes the interaction between humanistic spirit and sports activities more obvious. It is necessary to emphasize the sports culture as the core of the sports culture, in the future international sports modernization competition and the status of conflict will be more prominent and important. The famous scholar of the United States of America in the civilizations of the conflict and the clash of civilizations and the reconstruction of the world order that the new century, the root causes of human conflict is different cultures and civilizations; and the basic roots of conflict is no longer ideology, But cultural differences; even that the conflict of civilization will dominate the world. From the perspective of culture and civilization to study and analyze the contradictions and development trends of modern society, highlighting the culture, civilization in social contradictions, the status of competition is extremely profound. As we do not guide: our students in the watch taekwondo, Sanda, free fighting and other activities to see a violent culture; the same we do not promote the words: foreigners appreciate China Qigong, China Tai Chi, China Kung Fu See the Hong Kong, Macao and Taiwan movies, television described in the special culture. Interactive research has a great reference value and practical significance for sports culture construction and sports civilization creation activities. The conflict between East and West civilization is inevitable, we should be a positive attitude and way to face the impact of Western civilization, with the unique cultural charm of the East, put themselves into the modern sports culture, into the Olympic movement.

The socialization of people includes teaching basic life skills, teaching social norms, pointing to life goals and cultivating social roles and so on. Once people from the original meaning of natural person break free of biological constraints, into a social person, it means that the community has mastered the basic life skills and social behavior norms, to establish their own life goals, to assume their own social roles The In the social activities of people engaged in a variety of social activities, including in physical exercise and training, socialization of people will intentionally or unintentionally put their own sports activities in the formation of ideas, sports ethics, behavior, etc. in a variety of Social activities through the corresponding carrier presented in the sports activities are through a variety of competition rules, skills, tactics, sports ethics, sports aesthetics, sports values and so on; these humanistic spirit is undoubtedly the socialization of the people made a variety of Preparation, through the activities of the dissemination of sports spirit, humanistic spirit, so that the socialization of sports can learn from the migration to the process of socialization of the process, which will greatly enrich and improve the cultural humanities.

Therefore, the socialization of sports is through the interaction between sports and people, to promote the process of human socialization. Especially at the beginning of the birth of sports, as a specific cultural content, through a specific scenario (the implementation of physical education) to a specific person (original early people) specialization to master the specific social and historical 
experience of people, namely sports Socialization is the main means and intermediary of human socialization. To the modern, with the socialization of sports increasingly attention and advancement, sports socialization has become a modern socialization must be part of the experience, and will eventually become an important way of life of modern people, the national fitness campaign to focus on the school, Compulsory education makes every student have the right and obligation to learn sports, and thus have accepted the socialization of sports education. But in any case, sports socialization is only a certain degree of personal social means and intermediaries, rather than the ultimate goal.

\section{Conclusion}

At the same time, there is a positive and negative effect of the humanistic spirit coexisting at the same time; in the establishment of the individual-oriented, the existence of the socialism of the socialist market economy is not yet mature. The concept of individualism, egoism, loss of humanism breeding; access to individual autonomy after the distortion of the right to trade, all to the money to see; the introduction of competition mechanism soon evolved into tricky, widening gap between rich and poor; emphasis on sports scores, Benefits and then reduced to quick success, unsustainable / short-term behavior and so on. The emergence of a negative effect indicates that part of the social humanistic spirit is lost. Black whistle, the existence of false ball market is also a certain extent that the loss of sports morals, sports humanistic spirit of the decline.

\section{Acknowledgements}

2016 Jiangsu Province social education planning project: community sports education instructor team construction research

No.: JSS-L-2016021

\section{References}

[1] Yu Wenqian, Ren Bing. Analysis of the value of competitive humanistic spirit [J]. Journal of Sports Culture, 2004 (07)

[2] Xue Liucheng. Sports and humanistic spirit [J]. Sports Culture Guide, 2002 (03)

[3] Jiang Yi, Wang Lijuan, Ma Yucheng, Sun Jiancui, Hu Ming. Sports humanistic spirit [J]. Sports literature, 2001 (03)

[4] Li Qingjun. The humanistic spirit and significance of sports [J]. Mang species, 2012 (23)

[5] Silver ornaments of men's iconic ornaments [J]. Scientific fitness Bodybuilders, 2005 (07) 